\title{
Spine Plasticity in the Motor Cortex
}

\author{
Xinzhu Yu and \\ Department of Molecular, Cell and Developmental Biology, University of California Santa Cruz, \\ Santa Cruz, CA 95064, USA xyu@biology.ucsc.edu \\ Yi Zuo \\ Department of Molecular, Cell and Developmental Biology, University of California Santa Cruz, \\ Santa Cruz, CA 95064, USA zuo@biology.ucsc.edu
}

\section{Summary of recent advances}

Dendritic spines are the postsynaptic sites of the majority of excitatory synapses in the mammalian central nervous system. The morphology and dynamics of dendritic spines change throughout the lifespan of animals, in response to novel experiences and neuropathologies. New spines form rapidly as animals learn new tasks or experience novel sensory stimulations. This is followed by a selective elimination of previously existing spines, leading to significant synaptic remodeling. In the brain damaged by injuries or neurological diseases, spines in surviving cortical regions turn over substantially, potentially forming new synaptic connections to adopt the function lost in the damaged region. These findings suggest that spine plasticity plays important roles in formation and maintenance of a functional neural circuitry.

\section{Introduction}

The mammalian cortex is composed of columnar aggregates of neurons that share similar functional properties, such as orientation selectivity in the visual cortex or muscle movement control in the motor cortex. Functional maps in different cortical regions are capable of rapid and long-lasting reorganization throughout the animal's life, which is associated with novel experiences and pathologies. In the motor cortex, learning a new motor task is accompanied by expansion of the functional representation of task-related muscle movements in rats, primates and humans [1-3]. During the recovery following stroke or injury, surviving cortical regions adopt the function of damaged tissues [4-6]. In the visual cortex, the retinotopic map remodels following retinal lesions, associated with a massive rewiring of synaptic structures [7]. It has been proposed that intrinsic horizontal connections (i.e., intercolumnar and intracolumnar connections) of the cerebral cortex serve as a structural substrate for map plasticity. Pyramidal neurons establish these connections by extending long, horizontal axon collaterals that form excitatory synapses with their postsynaptic partners.

The synapse is the site of information exchange in the central nervous system. In the mammalian brain, the vast majority of excitatory glutamatergic synapses are formed between presynaptic axonal en passant boutons and postsynaptic dendritic spines. Dendritic

(C) 2010 Elsevier Ltd. All rights reserved.

Correspondence to: Yi Zuo.

Publisher's Disclaimer: This is a PDF file of an unedited manuscript that has been accepted for publication. As a service to our customers we are providing this early version of the manuscript. The manuscript will undergo copyediting, typesetting, and review of the resulting proof before it is published in its final citable form. Please note that during the production process errors may be discovered which could affect the content, and all legal disclaimers that apply to the journal pertain. 
spines are small protrusions emanating from dendritic shafts. Not only are spines heterogeneous in shape, their density also varies among different types of neurons and in different developmental stages [8]. Spines contain all the essential components required for postsynaptic signaling and plasticity and, thus, serve as good indicators of modifications in synaptic connectivity [9-11]. Recent studies have revealed dynamics of individual, fluorescently labeled dendritic spines over time in various cortical regions of living mice using two-photon imaging, and demonstrated that sensory experience dramatically affects spine stability (see reviews [12-14]). However, relatively little is known about spine dynamics in the motor cortex, how motor learning affects the connectivity of the neural circuitry, or how memory is structurally encoded in the intact brain.

Here, we will first review earlier studies on the functional and structural plasticity of synapses in the mammalian motor cortex. Next, we will move to the living brain and discuss recent examinations of spine dynamics during development and learning, including a comparative analysis of different cortical regions. Finally we will talk about some in vitro and in vivo studies on altered spine morphology and dynamics under pathological conditions.

\section{Functional and structural plasticity of synapses in the motor cortex \\ Functional plasticity of synapses}

Integration of synaptic signals is critical to the functional organization of neural circuitry. Long-term potentiation (LTP) and long-term depression (LTD) lead to changes in synaptic efficacy and have been proposed to be candidate mechanisms for learning-induced plasticity in the motor cortex. Evidence supporting this hypothesis comes from studies on both animals and humans.

Training rats with a skilled reaching task has been shown to strengthen horizontal connections in both layer I and layer II/III motor cortex contralateral to the trained limb, resulting in elevated amplitudes of field potentials $[15,16]$. Moreover, after the animal acquires the new motor skill, LTP is reduced, while LTD is enhanced [16] (Figure 1a,b). In humans, learning of novel hand movements has also been found to prevent the subsequent induction of LTP-like plasticity, while enhancing LTD-like plasticity [17]. The occlusion of further LTP induction in the post-learning brain suggests that LTP or LTP-like plasticity happens during motor learning.

In addition, while elevated field potentials persist long after initial learning acquisition, both LTP and LTD thresholds shift upward. As a consequence, the elevated baseline of synaptic efficacy is placed back to the middle of the LTP/LTD operating range, ensuring the possibility of further synaptic strengthening [18] (Figure 1b). Furthermore, electrical induction of LTP/LTD or LTP/LTD-like plasticity in the motor cortex in vivo before or during motor learning interferes with the learning process [19-21], providing further evidence to support LTP/LTD as a mechanism for learning acquisition of motor skills.

\section{Structural changes of synapses}

Many lines of evidence have also shown that synaptic structural changes are associated with functional changes of neural circuitry. In the rat motor cortex, induction of LTP in the forelimb region increases spine density of layer III and layer V pyramidal neurons, and expands the forelimb representation [22]. In contrast, induction of LTD decreases spine density [23], and shrinks the forelimb representation [24]. Learning-induced LTP occlusion, as discussed above, has also been shown to be associated with enlargement of spine heads in layer I of the motor cortex [15]. 
For decades, both electron microscopy (EM) and the Golgi staining method have been used to examine synapse/spine numbers in the motor cortex following motor skill learning. Despite the general belief that learning promotes synaptogenesis, data from different experimental paradigms and methods have resulted in diverse and somewhat conflicting conclusions. For example, EM analysis has indicated that motor learning has no effect on synapse density, but increases the synapse/neuron ratio in both layer II/III and layer V motor cortex contralateral to the trained forelimb [1,25]. In contrast, spine counting reveals that there is a decrease in spine density of layer III neurons, yet no effect on spine density in layer $\mathrm{V}$ pyramidal neurons in the motor cortex following motor skill training [26]. The layer-dependent changes in spine density imply that a sub-population, rather than all, of the neurons in the motor cortex responds to learning.

\section{Spine dynamics in the living brain}

The advent of high-resolution time-lapse imaging in conjunction with fluorescent molecular tools enables the visualization of synaptic structures in living animals. Using two-photon microscopy and transgenic animals in which a small population of neurons is fluorescently labeled, turnover and morphological changes of postsynaptic dendritic spines have been examined in various cortical regions, both during development and in association with experience and learning. While long-term in vivo imaging has revealed a global stability of dendritic arborization of cortical layer $\mathrm{V}$ neurons [27,28], spine dynamism and morphological changes have been reported throughout the cerebral cortex during development and in adulthood.

\section{Spine dynamics in developing and adult brains}

Despite the debate on the exact degree of spine dynamics, it is generally believed that dendritic spines change their morphology and turn over rapidly in developing animals but become much more stable in adults. During early postnatal stages, spines of cortical neurons are highly plastic, changing length and appearing/disappearing within tens of minutes $[29,30]$. Both spine motility and turnover decrease with increasing age. In adolescence, while spine turnover rates are comparable [31,32]; spine motility is intrinsically different in various cortical regions, high in somatosensory and auditory cortices while low in visual cortex [32]. Rewiring visual input into the auditory cortex at birth does not alter spine motility [32]. At this stage, spine elimination is significantly higher than spine formation throughout the cerebral cortex, leading to a gradual reduction in total spine number during postnatal development [28,31,33-35]. In contrast to adolescence, total spine numbers in all examined regions remain unchanged over time in adulthood, due to comparable rates of spine formation and elimination $[28,31,33-36]$. While the majority of spines stay stable, a subset of them constantly turns over [31,34]. Regardless of the divergence in spine classifications and calculation methods used in different studies, the consensus in the field is that the proportion of stable spines increases gradually from adolescence to adulthood $[27,30,31,34,35,37]$. For example, over $30 \%$ of spines are lost in mouse visual cortex from one to two months old of age, whereas $~ 96 \%$ spines in adults ( $>4$ months old) have a halflife more than 13 months [35]. While the high stability of spines provides a potential structural basis for long-term information storage in the brain, the plasticity of spines offers the brain a capability to rewire in response to novel experiences.

\section{Spine remodeling during motor skill learning}

Two recent studies further investigate spine dynamics during and after motor learning. $\mathrm{Xu}$ and colleagues train mice with a forelimb reaching task. They find that new spines are formed within one hour after initiation of motor skill learning in apical dendrites of layer $\mathrm{V}$ pyramidal neurons residing in the contralateral motor cortex [28] (Figure 1c,d). A similar 
observation is made by Yang et al., using an accelerated rotarod running task, in which spine formation increases within two days of training [37]. The degree of spine formation is closely associated with the degree of learning acquisition [28], as well as maintenance of the skill [37]. These de novo spines could provide a route to enlarge the memory storage capacity of the brain by creating new synaptic connections [38]. Moreover, this rapid spinogenesis during initial learning is followed by enhanced spine elimination, making total spine number return to the control level after prolonged training (Figure 1c,d). This elimination is selective for the spines that have existed before training, while the new spines induced during learning are preferentially stabilized during subsequent training, enduring long after training stops [28].

One of the most unique characteristics of motor learning is the fact that, once a motor behavior is learned, further maintenance of the motor skill does not require constant practice (Figure 1a). Xu et al. have shown that retraining of the same motor skill months later does not enhance spine dynamics (Figure 1d), suggesting that the circuitry needed for performing such motor tasks is made during initial training and maintained afterwards. However, training these pretrained animals with a novel motor skill continues to induce a robust spinogenesis in the primary motor cortex, suggesting that different motor memories are stored at different synaptic locations [28].

Together, these two studies suggest a critical role of long-lasting synaptic reorganization in formation of durable motor memories. However, despite the nice correlation of spine dynamics and learning behaviors illustrated in these studies, their causal relationship remains unclear. Genetic approaches to target and manipulate learning-related spines will be required to further address this question.

\section{Experience-dependent spine plasticity outside the motor cortex}

Experience-dependent spine plasticity has been found in many other systems in both developing and mature animals. In the barrel cortex, while enriched environment and learning paradigms promote spine formation [37,39], experience is also essential for the profound synapse pruning during adolescent development [33]. In the visual system, monocular deprivation (MD) doubles the rate of spine formation and increases the spine density in the apical dendrites of layer $\mathrm{V}$ neurons in the binocular cortex of adult mice. Restoring the binocular vision returns spine dynamics to the baseline. However, many MDinduced spines persist during binocular deprivation, providing a structural basis for the rapid functional shift during subsequent MD [36,40]. Recently, another elegant study investigates spine dynamics in the forebrain nucleus $\mathrm{HVC}$, a site where auditory information and motor representation merge in songbirds. Using lentivirus/GFP constructs to label neurons in HVC, the authors follow the spine dynamics in HVC during song learning in birds. Their data show that a higher level of spine turnover before tutoring correlates with greater capacity for subsequent song imitation. Furthermore, song learning experience triggers rapid stabilization of dendritic spines, and enhances spontaneous synaptic activity of these neurons [41].

\section{Altered spine morphology and dynamics under pathologies}

While experience-dependent modification of spine plasticity provides a cellular mechanism underlying learning and memory, abnormal spine morphology and dynamics are hallmarks of injuries and neurological diseases. In Alzheimer's disease (AD), a dramatic spine loss has been observed in the vicinity of $\beta$-amyloid plaques in the living cortex of transgenic $\mathrm{AD}$ mice $[42,43]$. Fragile X Syndrome (FXS) is characterized by an abundance of immature postsynaptic dendritic spines. A recent study has revealed a delayed downregulation of spine turnover and an increase of immature spines in layer II/III neurons during early postnatal stage in FXS mice [30]. In the motor cortex, spinal cord injury leads to spine remodeling: 
spine density of cortical pyramidal neurons decreases initially and partially recovers later on, together with enlarged spine heads and increased spine lengths [44]. Enriched environment and transplant/neurotrophin-3 treatments abolish such injury-induced spine morphological changes, providing potential candidates for further therapies [45]. Using live imaging, recent studies examine the dendritic and spine remodeling in the sensorimotor cortex following photothrombotic-induced stroke. These studies show that peri-infarct dendrites are exceptionally plastic, with elevated spine formation extending up to 6 weeks after stroke $[46,47]$. Furthermore, such synapse rewiring is closely associated with the functional remodeling that occurs during the recovery period [48]. These studies provide a better understanding of the relationship between spine alterations and brain dysfunctions, and offer valuable insights into pathogenesis and therapeutics of neurological diseases and injuries.

\section{Conclusion}

An important feature of the mammalian cortex is the capability of rapid and long-lasting functional reorganization. Our understanding of the morphological plasticity of spines, as well as their modifications with learning and altered brain functions in the living mouse cortex, highlights the significance of spines in the functional reorganization. In the motor system, current in vivo evidence indicates that spinogenesis occurs rapidly after motor learning is initiated and that a large population of these new spines persists while animals maintain motor skill performance, suggesting de novo spines as the underlying mechanism of learning. So far, changes in synaptic strength [16] and reorganization of the functional map [1] have been observed at a relatively late phase of motor learning, in contrast to the immediate spinogenesis observed in vivo [28]. Further investigation of the relationship between spine remodeling and motor functional map reorganization will provide valuable information to understanding the mechanisms underlying motor learning. Some recent studies combine in vivo imaging of synaptic structures with functional imaging (e.g. intrinsic optic imaging) or electrophysiological examination to address this question [7,27,48]. Twophoton calcium imaging, using $\mathrm{Ca}^{2+}$ sensitive dye or genetically encoded $\mathrm{Ca}^{2+}$ indicators, has monitored the activity of spatially defined neuronal population in the mammalian cortex, and led to a direct observation of functional neuronal clusters in the awake mouse motor cortex. It is shown that neurons involved in different responses intermingle spatially [49], while the temporal correlation between neurons decreases with the distance [50]. Moreover, when mice are trained with an odor-selective licking task, correlations of coincident activity for neurons with the same response types increase with learning. This suggests that learning creates a local network of functionally related neurons in the motor cortex [49].

The mammalian cortex is a laminar structure. Neurons in different cortical layers have different local and subcortical connections [51]. To date, the majority of in vivo, dendritic spine imaging data has been collected from two transgenic lines - the YFP-H line and the GFP-M line. Both lines use the thy- 1 promoter to drive fluorescent protein expression selectively in a subset of cortical neurons [52,53]. The studies described above mostly investigate dynamics of spines on apical dendrites of layer $V$ neurons. Whether changes in spine dynamics triggered by motor learning are restricted to these neurons remains unclear. It has been shown that spine dynamics of layer II/III neurons do not change after MD [36]. Thus, it will be important to explore structural plasticity in other cell types.

Finally, spines are postsynaptic components of excitatory synapses. It is to be expected that modifications in presynaptic axonal boutons also participate in motor cortex plasticity. Using the same thy- 1 transgenic mice, previous studies have investigated axon terminal stability in vivo. These studies find that axon bouton dynamics are cell-type specific [54], and axonal terminals are more stable than dendritic spines in general [32,54]. Studies 
examining axonal bouton changes in the motor cortex and during motor learning remain to be done.

\section{Acknowledgments}

We thank David States and Drs. Ju Lu, Denise Garcia for critical comments on this manuscript. This work was supported by grants from the Ellison Medical Foundation, the DANA Foundation, and the National Institutes of Aging to Y.Z.

\section{References and recommended reading}

Papers of particular interest, published within the annual period of review, have been highlighted as:

- of special interest

•• of outstanding interest

1. Kleim JA, Hogg TM, VandenBerg PM, Cooper NR, Bruneau R, Remple M. Cortical synaptogenesis and motor map reorganization occur during late, but not early, phase of motor skill learning. $\mathrm{J}$ Neurosci 2004;24:628-633. [PubMed: 14736848]

2. Nudo RJ, Milliken GW, Jenkins WM, Merzenich MM. Use-dependent alterations of movement representations in primary motor cortex of adult squirrel monkeys. J Neurosci 1996;16:785-807. [PubMed: 8551360]

3. Rosenkranz K, Kacar A, Rothwell JC. Differential modulation of motor cortical plasticity and excitability in early and late phases of human motor learning. J Neurosci 2007;27:12058-12066. [PubMed: 17978047]

4. Nudo RJ. Mechanisms for recovery of motor function following cortical damage. Curr Opin Neurobiol 2006;16:638-644. [PubMed: 17084614]

5. Murphy TH, Corbett D. Plasticity during stroke recovery: from synapse to behaviour. Nat Rev Neurosci 2009;10:861-872. [PubMed: 19888284]

6. Ghosh A, Haiss F, Sydekum E, Schneider R, Gullo M, Wyss MT, Mueggler T, Baltes C, Rudin M, Weber B, et al. Rewiring of hindlimb corticospinal neurons after spinal cord injury. Nat Neurosci 13:97-104. [PubMed: 20010824]

7•. Keck T, Mrsic-Flogel TD, Vaz Afonso M, Eysel UT, Bonhoeffer T, Hubener M. Massive restructuring of neuronal circuits during functional reorganization of adult visual cortex. Nat Neurosci 2008;11:1162-1167. [PubMed: 18758460] [In this study, the authors combine intrinsic optic imaging and two-photon imaging to study the functional and structural reorganization of the mouse visual cortex following local retinal lesions. They find that a large-scale turnover of dendritic spines in the adult visual cortex correlates with the functional remodeling of retinotopic maps.]

8. Nimchinsky EA, Sabatini BL, Svoboda K. Structure and function of dendritic spines. Annu Rev Physiol 2002;64:313-353. [PubMed: 11826272]

9. Segal M. Dendritic spines and long-term plasticity. Nat Rev Neurosci 2005;6:277-284. [PubMed: 15803159]

10. Harms KJ, Dunaevsky A. Dendritic spine plasticity: looking beyond development. Brain Res 2007;1184:65-71. [PubMed: 16600191]

11. Tada T, Sheng M. Molecular mechanisms of dendritic spine morphogenesis. Curr Opin Neurobiol 2006;16:95-101. [PubMed: 16361095]

12. Alvarez VA, Sabatini BL. Anatomical and physiological plasticity of dendritic spines. Annu Rev Neurosci 2007;30:79-97. [PubMed: 17280523]

13. Holtmaat A, Svoboda K. Experience-dependent structural synaptic plasticity in the mammalian brain. Nat Rev Neurosci 2009;10:647-658. [PubMed: 19693029]

14. Bhatt DH, Zhang S, Gan WB. Dendritic spine dynamics. Annu Rev Physiol 2009;71:261-282. [PubMed: 19575680] 
15•. Harms KJ, Rioult-Pedotti MS, Carter DR, Dunaevsky A. Transient spine expansion and learninginduced plasticity in layer 1 primary motor cortex. J Neurosci 2008;28:5686-5690. [PubMed: 18509029] [Recording from layer I horizontal connections in the rat motor cortex, the authors show that skilled reaching task increases the baseline amplitudes of field potentials, and occludes the induction of LTP in the motor cortex contralateral to the trained limb. These functional changes are associated with the increase in spine width in the layer I.]

16. Rioult-Pedotti MS, Friedman D, Donoghue JP. Learning-induced LTP in neocortex. Science 2000;290:533-536. [PubMed: 11039938]

17. Ziemann U, Ilic TV, Pauli C, Meintzschel F, Ruge D. Learning modifies subsequent induction of long-term potentiation-like and long-term depression-like plasticity in human motor cortex. $\mathrm{J}$ Neurosci 2004;24:1666-1672. [PubMed: 14973238]

18. Rioult-Pedotti MS, Donoghue JP, Dunaevsky A. Plasticity of the synaptic modification range. J Neurophysiol 2007;98:3688-3695. [PubMed: 17913995]

19. Hodgson RA, Ji Z, Standish S, Boyd-Hodgson TE, Henderson AK, Racine RJ. Training-induced and electrically induced potentiation in the neocortex. Neurobiol Learn Mem 2005;83:22-32. [PubMed: 15607685]

20. Jung P, Ziemann U. Homeostatic and nonhomeostatic modulation of learning in human motor cortex. J Neurosci 2009;29:5597-5604. [PubMed: 19403826]

21. Iezzi E, Suppa A, Conte A, Agostino R, Nardella A, Berardelli A. Theta-burst stimulation over primary motor cortex degrades early motor learning. Eur J Neurosci 31:585-592. [PubMed: 20105229]

22. Monfils MH, VandenBerg PM, Kleim JA, Teskey GC. Long-term potentiation induces expanded movement representations and dendritic hypertrophy in layer $\mathrm{V}$ of rat sensorimotor neocortex. Cereb Cortex 2004;14:586-593. [PubMed: 15054074]

23. Monfils MH, Teskey GC. Induction of long-term depression is associated with decreased dendritic length and spine density in layers III and V of sensorimotor neocortex. Synapse 2004;53:114-121. [PubMed: 15170823]

24. Teskey GC, Young NA, van Rooyen F, Larson SE, Flynn C, Monfils MH, Kleim JA, Henry LC, Goertzen CD. Induction of neocortical long-term depression results in smaller movement representations, fewer excitatory perforated synapses, and more inhibitory synapses. Cereb Cortex 2007;17:434-442. [PubMed: 16547346]

25. Kleim JA, Lussnig E, Schwarz ER, Comery TA, Greenough WT. Synaptogenesis and Fos expression in the motor cortex of the adult rat after motor skill learning. J Neurosci 1996;16:45294535. [PubMed: 8699262]

26. Kolb B, Cioe J, Comeau W. Contrasting effects of motor and visual spatial learning tasks on dendritic arborization and spine density in rats. Neurobiol Learn Mem 2008;90:295-300. [PubMed: 18547826]

27. Trachtenberg JT, Chen BE, Knott GW, Feng G, Sanes JR, Welker E, Svoboda K. Long-term in vivo imaging of experience-dependent synaptic plasticity in adult cortex. Nature 2002;420:788794. [PubMed: 12490942]

28••. Xu T, Yu X, Perlik AJ, Tobin WF, Zweig JA, Tennant K, Jones T, Zuo Y. Rapid formation and selective stabilization of synapses for enduring motor memories. Nature 2009;462:915-919. [PubMed: 19946267] [In this study, the authors examine spine dynamics in vivo during a forelimb reaching task. They find that new spines form rapidly in the forelimb motor cortex, contralateral to the trained limb. These new spines are preferentially stabilized during subsequent training and endure long after training stops. Furthermore, different motor skills are encoded by different sets of synapses. Practice of novel, but not previously learned, tasks further promotes spinogenesis in adulthood.]

29. Lendvai B, Stern EA, Chen B, Svoboda K. Experience-dependent plasticity of dendritic spines in the developing rat barrel cortex in vivo. Nature 2000;404:876-881. [PubMed: 10786794]

30. Cruz-Martin A, Crespo M, Portera-Cailliau C. Delayed stabilization of dendritic spines in fragile X mice. J Neurosci 30:7793-7803. [PubMed: 20534828]

31. Zuo Y, Lin A, Chang P, Gan WB. Development of long-term dendritic spine stability in diverse regions of cerebral cortex. Neuron 2005;46:181-189. [PubMed: 15848798] 
32. Majewska AK, Newton JR, Sur M. Remodeling of synaptic structure in sensory cortical areas in vivo. J Neurosci 2006;26:3021-3029. [PubMed: 16540580]

33. Zuo Y, Yang G, Kwon E, Gan WB. Long-term sensory deprivation prevents dendritic spine loss in primary somatosensory cortex. Nature 2005;436:261-265. [PubMed: 16015331]

34. Holtmaat AJ, Trachtenberg JT, Wilbrecht L, Shepherd GM, Zhang X, Knott GW, Svoboda K. Transient and persistent dendritic spines in the neocortex in vivo. Neuron 2005;45:279-291. [PubMed: 15664179]

35. Grutzendler J, Kasthuri N, Gan WB. Long-term dendritic spine stability in the adult cortex. Nature 2002;420:812-816. [PubMed: 12490949]

36••. Hofer SB, Mrsic-Flogel TD, Bonhoeffer T, Hubener M. Experience leaves a lasting structural trace in cortical circuits. Nature 2009;457:313-317. [PubMed: 19005470] [The authors study spine dynamics during repetitive monocular deprivation (MD) in the mouse visual cortex. They find that MD increases spine formation selectively in the apical dendrites of layer $\mathrm{V}$ neurons in the binocular region. And many MD-induced spines persist during the binocular vision recovery, and quickly enlarge during the subsequent MD, providing a structural basis for the rapid functional shift.]

37••. Yang G, Pan F, Gan WB. Stably maintained dendritic spines are associated with lifelong memories. Nature 2009;462:920-924. [PubMed: 19946265] [The authors examine spine dynamics in both enriched environment and rotarod task in the mouse sensory and motor cortex by live imaging. They show that new experience induces spines formation. A small portion of these experience-induced new spines, together with most spines formed early during development and surviving experience-dependent elimination, are preserved throughout the life of an animal.]

38. Stepanyants A, Chklovskii DB. Neurogeometry and potential synaptic connectivity. Trends Neurosci 2005;28:387-394. [PubMed: 15935485]

39. Holtmaat A, Wilbrecht L, Knott GW, Welker E, Svoboda K. Experience-dependent and cell-typespecific spine growth in the neocortex. Nature 2006;441:979-983. [PubMed: 16791195]

40. Hofer SB, Mrsic-Flogel TD, Bonhoeffer T, Hubener M. Prior experience enhances plasticity in adult visual cortex. Nat Neurosci 2006;9:127-132. [PubMed: 16327785]

$41 \bullet$. Roberts TF, Tschida KA, Klein ME, Mooney R. Rapid spine stabilization and synaptic enhancement at the onset of behavioural learning. Nature 463:948-952. [PubMed: 20164928] [In this study, the authors follow spine dynamics in HVC during song learning in birds. They find that a higher level of spine turnover before tutoring is correlated with greater capacity for subsequent song imitation. Furthermore, song learning experience triggers rapid stabilization of HVC neuron spines, and increases spontaneous synaptic activity of these neurons.]

42. Tsai J, Grutzendler J, Duff K, Gan WB. Fibrillar amyloid deposition leads to local synaptic abnormalities and breakage of neuronal branches. Nat Neurosci 2004;7:1181-1183. [PubMed: 15475950]

43. Spires TL, Meyer-Luehmann M, Stern EA, McLean PJ, Skoch J, Nguyen PT, Bacskai BJ, Hyman BT. Dendritic spine abnormalities in amyloid precursor protein transgenic mice demonstrated by gene transfer and intravital multiphoton microscopy. J Neurosci 2005;25:7278-7287. [PubMed: 16079410]

44. Kim BG, Dai HN, McAtee M, Vicini S, Bregman BS. Remodeling of synaptic structures in the motor cortex following spinal cord injury. Exp Neurol 2006;198:401-415. [PubMed: 16443221]

45. Kim BG, Dai HN, McAtee M, Bregman BS. Modulation of dendritic spine remodeling in the motor cortex following spinal cord injury: effects of environmental enrichment and combinatorial treatment with transplants and neurotrophin-3. J Comp Neurol 2008;508:473-486. [PubMed: 18338331]

46. Brown CE, Li P, Boyd JD, Delaney KR, Murphy TH. Extensive turnover of dendritic spines and vascular remodeling in cortical tissues recovering from stroke. J Neurosci 2007;27:4101-4109. [PubMed: 17428988]

47. Brown CE, Boyd JD, Murphy TH. Longitudinal in vivo imaging reveals balanced and branchspecific remodeling of mature cortical pyramidal dendritic arbors after stroke. J Cereb Blood Flow Metab 30:783-791. [PubMed: 19920846] 
48• Brown CE, Aminoltejari K, Erb H, Winship IR, Murphy TH. In vivo voltage-sensitive dye imaging in adult mice reveals that somatosensory maps lost to stroke are replaced over weeks by new structural and functional circuits with prolonged modes of activation within both the periinfarct zone and distant sites. J Neurosci 2009;29:1719-1734. [PubMed: 19211879] [In this study, the authors use photothrombosis to induce local stroke in the forelimb region. They then follow spine dynamics and sensory-evoked functional map changes, using two-photon microscopy and the voltage sensitive dye. They show that during the recovery, the peri-infarct area exhibits high degree of dendritic spine remodeling and prolonged forelimb-evoked depolarization.]

49. Komiyama T, Sato TR, O'Connor DH, Zhang YX, Huber D, Hooks BM, Gabitto M, Svoboda K. Learning-related fine-scale specificity imaged in motor cortex circuits of behaving mice. Nature 464:1182-1186. [PubMed: 20376005]

50. Dombeck DA, Graziano MS, Tank DW. Functional clustering of neurons in motor cortex determined by cellular resolution imaging in awake behaving mice. J Neurosci 2009;29:1375113760. [PubMed: 19889987]

51. Anderson CT, Sheets PL, Kiritani T, Shepherd GM. Sublayer-specific microcircuits of corticospinal and corticostriatal neurons in motor cortex. Nat Neurosci 13:739-744. [PubMed: 20436481]

52. Feng G, Mellor RH, Bernstein M, Keller-Peck C, Nguyen QT, Wallace M, Nerbonne JM, Lichtman JW, Sanes JR. Imaging neuronal subsets in transgenic mice expressing multiple spectral variants of GFP. Neuron 2000;28:41-51. [PubMed: 11086982]

53. Yu J, Anderson CT, Kiritani T, Sheets PL, Wokosin DL, Wood L, Shepherd GM. Local-Circuit Phenotypes of Layer 5 Neurons in Motor-Frontal Cortex of YFP-H Mice. Front Neural Circuits 2008;2:6. [PubMed: 19129938]

54. De Paola V, Holtmaat A, Knott G, Song S, Wilbrecht L, Caroni P, Svoboda K. Cell type-specific structural plasticity of axonal branches and boutons in the adult neocortex. Neuron 2006;49:861875. [PubMed: 16543134] 
(a)

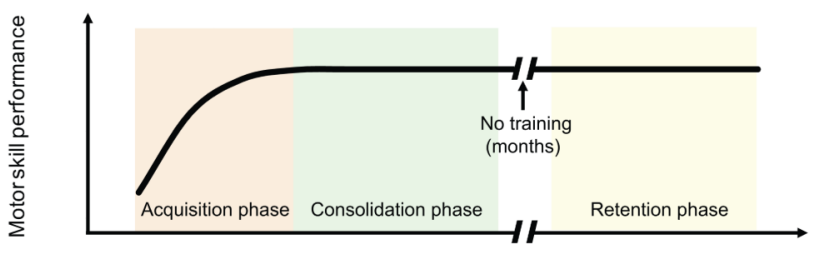

(b)

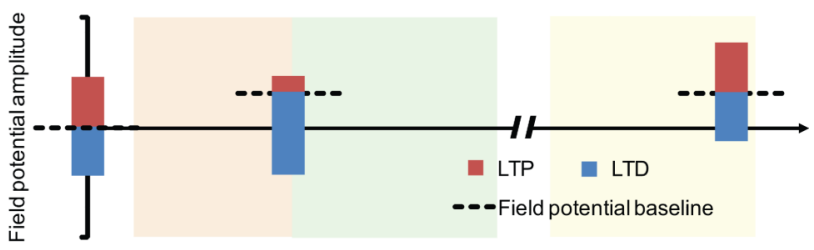

(c)

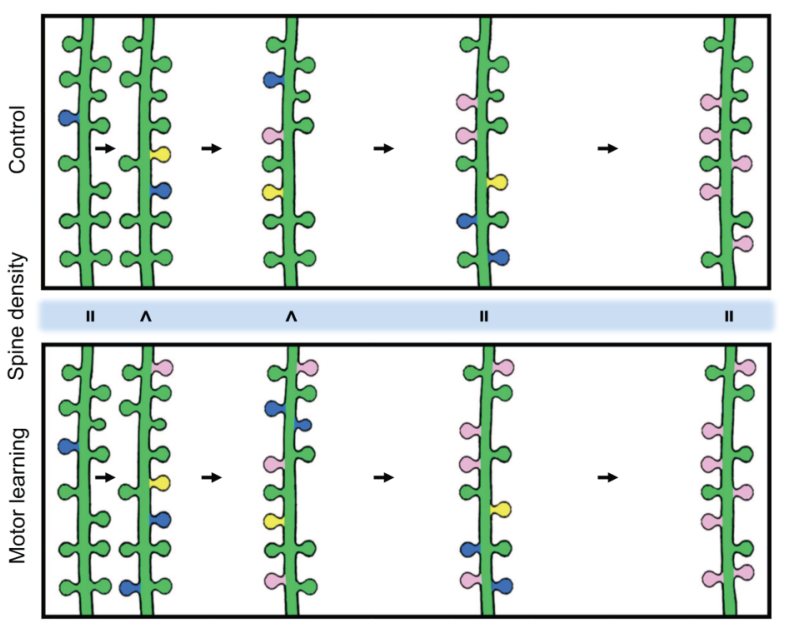

$\Omega$ Spines persisted

$\Omega$ Spines formed and persisted

$\Omega$ Spines eliminated

$\Omega$ Transient spines formed and eliminated

(d)
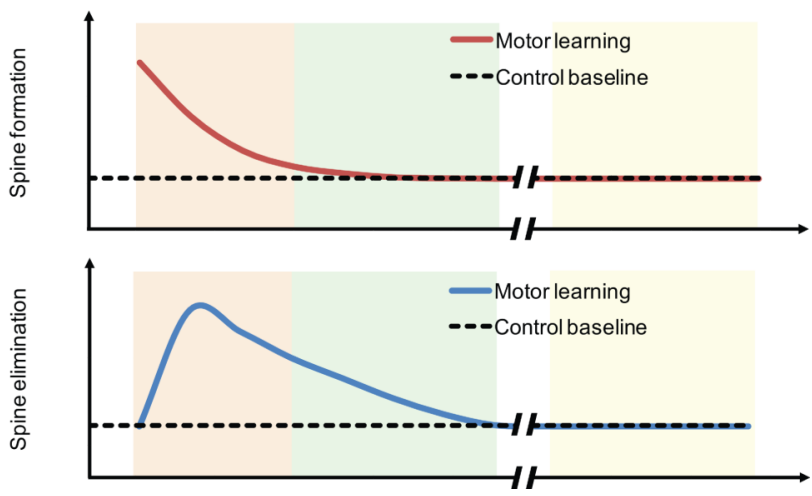

Figure 1.

Changes in synapse strengths and spine dynamics in the motor cortex during and after motor learning. (a) Three phases of motor learning: significant improvement of performance is observed in acquisition phase, and high performance is maintained during consolidation and retention phases. (b) Synaptic efficacy baseline and LTP/LTD modification range. Elevated baseline field potentials have been observed in layer I, II/III neurons in the motor cortex after learning acquisition. This leads to reduced LTP and enhanced LTD. In the retention phase, the synaptic modification range shifts upward with time, placing the elevated baseline back to the middle of the LTP/LTD operating range. (c) A schematic illustrating immediate and protracted spine dynamics in both control and trained animals. Learning-induced new 
spines are preferentially stabilized, while pre-existing spines are selectively removed, leading to the rewiring of the neural circuitry. Motor learning temporally increases spine density, which gradually returns back to the control level. (d) Time course of changes in spine formation and elimination. Motor learning leads to a rapid increase in spine formation, which is followed by delayed but prolonged spine elimination. 